\title{
Rancangan Explosive Detector Untuk Mengetahui Keberadaan Serta Jenis Bahan Peledak Dengan Membandingkan Besar Nilai Medan Magnet Menggunakan Arduino
}

\author{
M. Erwin Zakariya K. \\ Yuyun Suprapto \\ Akademi Teknik dan Keselamatan Penerbangan Surabaya
}

\begin{abstract}
This design was created as an alternative Explosive Detector equipment as well as provide additional help if at an airport not provided the proper equipment. Its equipment is not yet available Explosive Detector at some airport and its equipment is expensive, the writer wanted to make a design Explosive Detector with a low cost and designed with the latest technology. The design of Explosive Detector capable of detecting the presence and type of explosives by calculating a large magnetic field as well as large comparing magnetic field so they will know what kind of explosives were detected. The draft Explosive Detector uses Magnetometer sensor as the basic concept.
\end{abstract}

Keywords: Explosive Detector, low cost, magnetic field, Magnetometer sensor

\section{LATAR BELAKANG}

Belum tersedia nya peralatan explosive detector di beberapa bandar udara di Indonesia serta mahal nya dari peralatan ini sehingga penulis menginginkan membuat suatu rancangan explosive detector dengan biaya yang murah serta dirancang dengan teknologi terbaru. Rancangan penulis yang inginkan dapat mendekteksi keberadaan serta jenis bahan peledak dengan cara menganalisa perubahan medan magnet serta menghitung besar magnet suatu bahan peledak.

Dari uraian diatas, penulis ingin mencoba merancang alat sebagai alternative peralatan explosive detector namun rancangan peralatan yang penulis buat tidak bermaksud menggantikan alat pendekteksi konvensional tetapi untuk memberikan bantuan tambahan bila tidak tersedia peralatan yang memadai pada bandar udara.

\section{TUJUAN}

1. Membuat rancangan explosive detector dengan membandingkan besar nilai medan magnet untuk mengetahui keberadaan serta jenis bahan peledak

2. Membuat alternatif peralatan explosive detector dengan harga terjangkau serta teknologi terbaru.

\section{BENTUK PENELITIAN}

Hasil dari penelitian ini berupa produk alternatif explosive detector dengan kemampuan dapat mendektesi keberadaan bahan peledak dengan cara membandingkan besar nilai medan magnet bahan dengan harga terjangkau serta teknologi terbaru. Diharapkan dengan adanya alat ini dapat di gunakan 
pada Bandar udara yang tidak memiliki peralatan explosive detector konvensional, sehingga dapat meningkatkan keamanan penerbangan.

\section{RANCANGAN PENELITIAN}

Pada penelitian ini akan dirancang prototipe explosive detector dengan membandingkan besar nilai medan magnet untuk mengetahui keberadaan serta jenis bahan peledak menggunakan arduino. Rancangan ini dapat digunakan sebagai pengganti explosive detector konvensional. Rancangan Explosive Detector ini memiliki diagram blog seperti pada gambar 1.

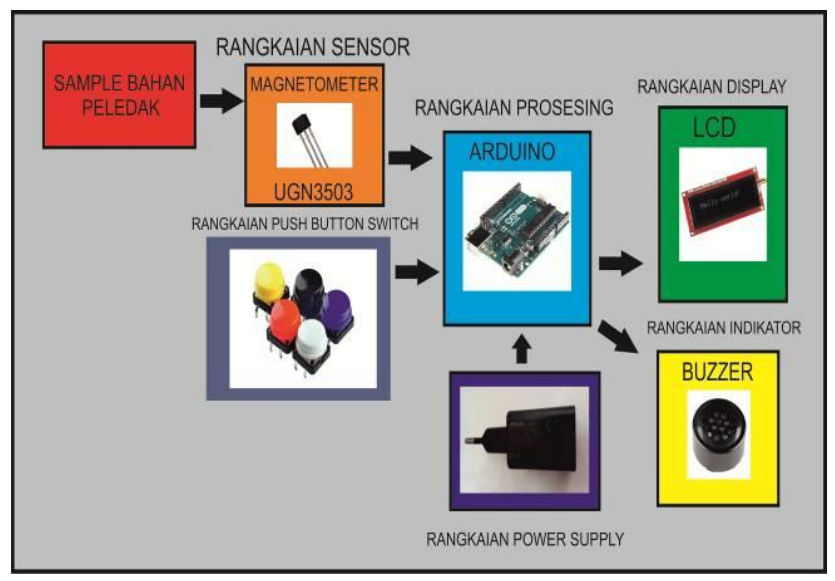

Gambar 1. Diagram blok rancangan Explosive Detector

Pada blog diagram diatas dibutuhkan sample bahan peledak yang memiliki nilai kuat medan magnet yang cukup sehingga dapat di gunakan sebagai sample. Lalu sample bahan peledak akan di sensor dengan rangkain sensor Magnetometer UGN3503. Sensor magnetometer UGN3503 sebagai sensor penghitung besar medan magnet dalam satuan Gauss. Sensor magnetometer UGN3503 digunakan dalam rancangan alat karena merupakan sensor yang sensivitif dengan sensitivitas 0 sampai 900 Gaus karena dapat menghitung perubahan dari kerapatan magnetic flux. Sensor magnetometer UGN3503 menggunakan power 5 volt.

Arduino Uno digunakan sebagai rangkaian prossesing. Pada rangkaian ini berisi beberapa program yang di dalamnya terdapat perintah - perintah yang dibuat sehingga Arduino dapat beroperasi sesuai dengan rancangan. Arduino mendapatkan input analog yang berasal dari sensor magnetometer UGN3503 dalam bentuk nilai tegangan. Sedangkan output arduino dihubungkan dengan LCD untuk menampilkan besar medan magnet dan kategori bahan peledak yang dideteksi.

Pada rangkaian display menggunakan LCD 16x2. LCD digunakan untuk menampilkan besar medan magnet, kategori dari bahan peledak serta mengindikasikan peringatan warning apabila besar medan magnet melebihi yang telah ditetapkan. LCD terhubung dengan I2C communication, I2C communication digunakan sebagai pengubah data serial pada LCD dirubah menjadi data digital.

Push Button dibutuhkan sebagai input Reset, Hold, serta Kalibrasi. Tombol Reset berfungsi sebagai mengembalikan nilai 0 Gauss setelah proses deteksi bahan peledak, tombol Hold berfungsi 
sebagai menampilkan nilai medan magnet terakhir saat proses deteksi, tombol Kalibrasi berfungsi sebagai penentuan batas peringatan atau warning.

Pada rancangan alat ini, supply tegangan diperoleh dari tegangan 220 Volt AC yang di peroleh dari source PLN. Power supply dapat merubah tegangan Input 220 Vac menjadi Output 5 Vdc. Output $5 \mathrm{Vdc}$ akan menjadi Input tegangan arduino sebesar $5 \mathrm{Vdc}$.

Rangkaian indikator yang digunakan pada rancangan alat adalah Buzzer. Buzzer digunakan sebagai indikator ketika alat start running, indikator apabila alat mampu mendekteksi kategori petasan serta indikator apabila besar medan magnet petasan melebihi batasan yang di tetapkan.

\section{PENGUKURAN DAN ANALISA}

\section{Pengukuran dan Analisa Power Supply}

Dilakukan pengukuran dan analisa power supply untuk mengetahui kinerja dari power supply dalam memberikan supply tegangan terhadap setiap komponen utama maupun komponen pendukung pada rancangan alat ini. Supply tegangan pada rancangan alat ini dapat diukur pada vec dan ground pada power supply.

Dari hasil pengukuran diperoleh data seperti pada tabel 1.

Tabel 1. Hasil Pengukuran Power Supply

\begin{tabular}{|c|c|c|}
\hline Hasil Perhitungan & Hasil Pengukuran & Keterangan \\
\hline 5 Volt & 4,9 Volt & Mendekati \\
\hline
\end{tabular}

Setelah dilakukan pengukuran dari rangkaian power supply hasil pengukuran keluaran tegangan untuk power supply berkisar antara 4,88 Vdc sampai dengan 5,04 Vdc. Hal ini menunjukkan bahwa power supply yang digunakan cukup stabil dan siap untuk mensupply rancangan peralatan.

\section{Pengukuran dan Analisa LCD ( Liquid Crystal Display )}

Pengukuran dan analisa LCD dilakukan untuk mengetahui kerja dari LCD dalam menampilkan karakter atau data sesuai dengan program yang direncanakan. LCD dipasang pada PORT DIG 2, 3, 9, 10, 11, 12 pada I2C 1602 serial module yang nanti terhubung dengan arduino. Dari hasil pengukuran diperoleh data seperti pada tabel 2.

Tabel 2. Hasil Pengukuran LCD

\begin{tabular}{|c|c|c|}
\hline Hasil Perhitungan & Hasil pengukuran & Keterangan \\
\hline 5 Volt & 4,9 Volt & Mendekati \\
\hline
\end{tabular}


Pada datasheet LCD 16x2 nilai Input Voltage pada pin 2 atau pin VDD sebesar 5 Vdc sedangkan pada pengukuran pada LCD menggunakan AVO meter dengan menghubungkan probe merah AVO meter dengan pin 2 atau pin VDD LCD dan probe hitam dengan pin 1 atau pin GND menunjukkan besar tegangan sebesar 4,9 Vdc. Hal ini menunjukkan bahwa nilai pada datasheet dengan nilai pengukuran pada AVO meter mendekati.

\section{Pengukuran dan Analisa I2C 1602 Serial Module}

Pengukuran dan analisa I2C 1602 Serial Module untuk mengetahui kinerja dari modul itu sendiri sebagai pengganti data serial dari LCD menjadi data digital yang akan di hubungkan dengan arduino. Tegangan pada I2C 1602 Serial Module ini dapat diukur pada vcc dan ground. Hasil pengukuran terhadap I2C 1602 Serial Module terlihat seperti pada tabel 3.

Tabel 3. Hasil pengukuran I2C 1602 Serial

\begin{tabular}{|c|c|c|}
\hline Hasil Perhitungan & Hasil pengukuran & Keterangan \\
\hline 5 Volt & 4,9 Volt & Mendekati \\
\hline
\end{tabular}

Pada datasheet I2C 1602 Serial Module Operating Voltage sebesar 5Vdc sedangkan pada pengukuran pada LCD menggunakan AVO meter dengan menghubungkan probe merah AVO meter dengan pin VCC dan probe hitam pin GND menunjukkan besar tegangan sebesar 4,9 Vdc. Hal ini menunjukkan bahwa nilai pada datasheet dengan nilai pengukuran pada AVO meter mendekati.

\section{Pengukuran dan Analisa Buzzer}

Pengukuran dan analisa Buzzer dilakukan untuk mengetahui kinerja dari Buzzer dalam menghasilkan output berupa suara sesuai dengan program yang telah di rencanakan. Pada rancangan alat ini, Buzzer dipasang pada PORT DIG 5. Hasil pengukuran buzzer seperti terlihat pada tabel 4.

Tabel 4. Hasil pengukuran Buzzer

\begin{tabular}{|c|c|c|}
\hline Inputan & Output pada Indikator Buzzer & Keterangan \\
\hline Low & Mati & Sesuai \\
\hline High & Nyala ( Bunyi ) & Sesuai \\
\hline
\end{tabular}

Berdasarkan hasil pengukuran Buzzer, ketika Inputan Low maka Buzzer tidak berbunyi sedangkan ketika Inputan High maka Buzzer akan berbunyi. Hal ini berarti Buzzer bekerja dengan normal. 


\section{Pengukuran dan Analisa Push Button Switch}

Pengukuran dan analisa Push Button dilakukan untuk mengetahui kinerja dari push button saat melakukan input Reset, Hold, serta kalibrasi. Tombol Reset berfungsi mengembalikan nilai 0 Gauss setelah di lakukan proses deteksi bahan peledak, tombol Hold berfungsi sebagai menampilkan nilai medan magnet terakhir saat proses deteksi, tombol Kalibrasi berfungsi sebagai penentuan nilai batas peringatan bahan peledak atau warning. Push Button Swicth pada rancangan alat ini dipasang pada POR DIG 11,10,9.

Pada Push Button Switch memiliki tegangan 5 Vdc. Pengukuran tegangan saat tombol di tekan dan tidak di tekan. Apabila push button ditekan maka besar tegangannya 0 Volt, sedangkan apabila push button tidak di tekan nilai tegangannya 5 volt. Hasil pengukuran sensor suhu yang telah dilakukan terlihat seperti pada tabel 5.

Tabel 5. Hasil pengukuran Push Button

\begin{tabular}{|c|c|c|c|}
\hline $\begin{array}{c}\text { Keadaan } \\
\text { Push } \\
\text { Button }\end{array}$ & $\begin{array}{c}\text { Hasil } \\
\text { Perhitungan }\end{array}$ & $\begin{array}{c}\text { Hasil } \\
\text { pengukuran }\end{array}$ & Keterangan \\
\hline $\begin{array}{c}\text { Tidak } \\
\text { ditekan }\end{array}$ & 5 Volt & 4 Volt & Mendekati \\
\hline Ditekan & 0 Volt & 0 Volt & Sesuai \\
\hline
\end{tabular}

Analisa pada pengukuran Push Button adalah saat tombol di tekan atau tidak di tekan. Apabila push button di tekan maka besar tegangan 0 Volt sedangkan apabila push button tidak di tekan nilai tegangan 4 Volt. Hal ini berarti hasil pengukuran sesuai.

\section{Pengukuran dan analisa nilai ADC ( Analog to Digital Converter )}

Pengukuran dan analisa ADC dilakukan dengan tujuan untuk mengetahui hasil konversi tegangan dengan menggunakan program ADC ( Analog to Digital Converter ) pada aplikasi Arduino. Pada rancangan alat ini, menggunakan ADC dengan resolusi 10 bit.

Dalam pengukuran ADC pada rancangan alat ini resolusi yang digunakan sebesar 10 bit maka level kuantitasinya adalah sebagai berikut :

\section{Level kuantisasi $=2^{\mathrm{n}}$, dimana $\mathbf{n}=$ Resolusi $($ bit $)$}

$$
\mathrm{n}=10 \text { bit, Level kuantisasi }=\mathbf{2}^{\mathbf{1 0}}=\mathbf{1 0 2 4}
$$

Untuk mengkonversikan bentuk ADC ( Analog to Digital ) ke tegangan dengan menggunakan rumus sebagai berikut : 
Nilai ADC $=$

\section{$\underline{\text { Tegangan }(\text { Volt })} \quad \times \mathrm{V}$ referensi}

\section{Nilai kuantisasi 1024}

Dalam pengukuran ADC ini menggunakan $\mathrm{V}$ referensi sebesar 5 volt, maka hasil perhitungan dari tampilan LCD ( program Arduino ) akan dibandingkan dengan hasil pengukuran dengan menggunakan avometer / multimeter. Hasil perhitungan dan pengkuran nilai ADC yang telah dilakukan terlihat seperti pada tabel 6.

Tabel 6. Hasil Perhitungan dan Pengukuran nilai ADC

\begin{tabular}{|c|c|c|c|}
\hline $\begin{array}{c}\text { Nilai Medan } \\
\text { Magnet }\end{array}$ & $\begin{array}{c}\text { Nilai ADC } \\
\text { perhitungan }\end{array}$ & $\begin{array}{c}\text { Nilai ADC Pada Serial } \\
\text { Monitor }\end{array}$ & Keterangan \\
\hline 0 Gauss & 518 & 519 & Mendekati \\
\hline 0,27 Gauss & 520 & 520 & Mendekati \\
\hline 0.53 Gauss & 522 & 521 & Mendekati \\
\hline 1,06 Gauss & 524 & 523 & Mendekati \\
\hline 1,33 Gauss & 526 & 524 & Mendekati \\
\hline 1,60 Gauss & 528 & 525 & Mendekati \\
\hline 2,3 Gauss & 530 & 528 & Mendekati \\
\hline 2,93 Gauss & 532 & 530 & 534 \\
\hline 3,99 Gauss & 536 & & \\
\hline
\end{tabular}

Pebandingan antara hasil perhitungan tegangan mendekati dengan hasil pengukuran menggunakan multimeter / avometer maupun pemacaan nilai ADC dan tampilan LCD. Hal ini menunjukkan bahwa program ADC yang terdapat di Arduino bekerja sesuai dengan program yang direncanakan.

\section{Pengukuran dan Analisa Sensor Magnetometer UGN3503}

Pengukuran dan analisa sensor dilakukan untuk mengetahui kemampuan sensor magnetometer UGN3503 dalam mendekteksi besar medan magnet pada sample bahan peledak yang digunakan pada alat Explosive Detector.

Pada proses pengukuran sensor menggunakan sample uji coba berupa petasan yang memiliki medan magnet yang berbeda sehingga akan di kategorikan bahan peledak A, B atau C. Hasil output 
dari proses pendeteksian oleh sensor berupa nilai ADC yang akan di bandingkan berdasarkan database yang telah di program. Dengan nilai ADC yang ada akan dilakukan klasifikasi berdasarkan besaran nilai ADC. Kemudian akan dilakukan sampling terhadap besaran nilai ADC untuk mengetahui kategori bahan peledak. Hasil perhitungan dan pengkuran sensor yang telah dilakukan terlihat seperti pada tabel 7.

Tabel 7. Data perbandingan nilai tegangan

\begin{tabular}{|c|c|c|c|}
\hline Nilai Medan Magnet & Perhitungan & Pengukuran & Keterangan \\
\hline 0 Gauss & 2,53 Volt & 2,54 Volt & Mendekati \\
\hline 0,27 Gauss & 2,54 Volt & 2,55 Volt & Mendekati \\
\hline 0.53 Gauss & 2,55 Volt & 2.56 Volt & Mendekati \\
\hline 1,06 Gauss & 2,56 Volt & 2,57 Volt & Mendekati \\
\hline 1,33 Gauss & 2,57 Volt & 2,58 Volt & Mendekati \\
\hline 1,60 Gauss & 2,58 Volt & 2,59 Volt & Mendekati \\
\hline 2,13 Gauss & 2,59 Volt & 2,60 Volt & Mendekati \\
\hline 2,93 Gauss & 2,60 Volt & 2,61 Volt & Mendekati \\
\hline 3,46 Gauss & 2,61 Volt & 2,62 Volt & Mendekati \\
\hline 3,99 Gauss & 2,62 Volt & 2,63 Volt & Mendekati \\
\hline
\end{tabular}

Data pada tabel 7 merupakan data perbandingan nilai tegangan yang terbaca pada serial monitor software arduino dan nilai tegangan yang diukur menggunakan AVO meter. Perubahan nilai Gauss mempengaruhi besar tegangan, namun perbedaan besar nilai tegangan sangat kecil sekali, maka dari itu diperlukan AVO digital agar pengukuran lebih akurat. Pebandingan antara tegangan yang terbaca pada serial monitor software arduino mendekati dengan hasil pengukuran menggunakan multimeter / avometer. Hal ini menunjukkan bahwa Sensor Magnetometer UGN3503 beroperasi dengan baik karena mampu mensensor besar medan magnet suatu bahan feromagnetik atau bahan magnetik dengan selisih yang kecil dan mampu di rubah menjadi tegangan dengan selisih yang kecil sehingga dapat dikatakan sensor Magnetometer UGN3503 memiliki sensitifitas yang baik.

\section{KESIMPULAN}

1. Sensor magnetometer UGN3503 dapat digunakan sebagai pendeteksi Dangerous Goods berupa bahan peledak petasan 
2. Sistem pendekteksian pada alat ini menggunakan sensor magnetometer UGN3503 dimana untuk mendekteksi sample diperlukan besar medan magnet dari bahan peledak tersebut.

3. Pemograman pada alat ini menggunakan mikrokontroller Arduino Uno yang bekerja berdasarkan hasil pendekteksian sensor berupa nilai ADC dan digunakan untuk menentukan hasil dari sistem.

\section{SARAN}

1. Untuk selanjutnya diharapkan Explosive Detector dapat mendekteksi banyak barang atau bahan tidak hanya petasan. Sehingga perlu dilakukan percobaan dengan unsur lain seperti bahan dinamit, black powder, ANFO, TNT (Trinitrotoluena) atau bahan peledak yang bersifat high explosive

2. Diperlukan desain packing dari alat yang lebih portable dan supply power menggunakan baterai agar alat dapat di operasikan tanpa selalu menggunakan sumber tegangan PLN.

\section{DAFTAR PUSTAKA}

IATA Dangerous Goods Regulations, 2011 ( Edisi 52 )

Djuandi, Feri. Pengenalan Arduino, Free Book Online, 2010

Saito, Taro. Buku Teks Kimia Anorganik Online, Free Book Online, 1996

Austin, George. T. Shreve's Chemical Process Industries, King Keong Printing CO.PTE.LTDRepublic of Singapore, 1984

Coey, J.M.D. Magnetism and Magnetic Materials, Cambridge University Press, 2009

Carver, Kraus. Electromagnetics. Kosaido Printing CO.LTD. Tokyo Japan, 1973

Wohlfarth, E.P. Handbook of Feromagnetic Materials. North Holland. 1980

Urbanski, Tadeusz. Chemistry and Technology of Explosive. Pergamon Press. 1964

Fordham, S. High Explosive and Propellants. Pergamon Press. 1980

Gardner, Julian W. Electronic Noses and Sensors for the Detection of Explosives. SpringerScience+Business Media. 2003

Hall Effect Sensing and Application. Honeywell

Popovic, R S . Hall Effect Devices. IOP Publishing. 2004

Meyer,Herbert W. History of Electricity and Magnetism. Burndy Library. 1972

Perry, Robert H. Perry's Chemical Engineers Handbook. The McGraw Hill companies. 2008

Shreve, R. Norris. The Chemical Process Industries. The McGraw Hill companies . 1956 